\title{
Science has a word for it
}

"I'M SORRY, but arranging for you to see Dr Smith in the next few weeks is going to be very difficult; he's delocalised between London and Geneva". So said a scientist on the phone to us recently. The thought of the fairly ample Dr Smith being a mere probability density function and subjected to an uncertainty principle started a train of thought about how scientists could enrich or befoul the English language.

Some jargon has, of course, already made the jump, sorry the transition, from the laboratory to everyday use-for instance half-life. Fall-out, an undesirable consequence in its scientific context which became a desirable one in its general usage has got even furtherto retirement. But there are riches untouched as yet, and others not well enough known. Here are a few examples.

world-line: 'If only I'd known you were in London yesterday, we could surely have made our world-lines intersect'. One way to have done this, of course, would have been to settle on a time and space window. That would have put up the collision cross-section by orders of magnitude.

hysteritic: Suitable as a descrption of management or bureaucracy. You push in one direction and you encounter resistance and delay: you reverse your direction of attack and lo and behold the self-same resistance and delay meets you.

boundary conditions: When you are looking around for a new job you specify certain requirements-rural environment, good schools in the neighbourhood, no overtime, easy access to London ... In short, boundary conditions. A search through the classified advertisements then yields a set of suitable jobs consistent with them: presumably these are called eigenfunctions. The salaries, or eigenvalues, often bear a strong similarity to each other. This is hardly surprising given the nature of the world. But scientists even have a word for that; degeneracy.

boeing: Not strictly a scientific word, of course, but refers to the behaviour of many scientists. Many laboratories have one person who is always flying off to conferences. He is said to be boeing around. I bo, you bo, he boes; though of course you and I don't do it.

orthogonal: A slightly derogatory term. 'His interests are pretty orthogonal to mine' indicates that of all the wealth of my interests, he can't find a thing in common with me. Other stronger insults are to imply that a colleague has limited bandwidth or, what comes to the same thing, high-Q - a narrow view of the world and an ability to go on and on when given the chance. Nor is calling someone non-linear polite. It suggests that under pressure they either fade or over-react.

deconvolution: Ask a simple question and some people, with complex transfer functions, convert your input into highly convoluted output. Deconvolution is simply finding out whether they said yes or no. You may also have a signal-to-noise ratio problem to contend with.

perturbation: invariably associated with an order. A first-order perturbation is very large indeed, such as getting married, having children, changing jobs. A second-order perturbation is trifling; for instance picking up a colleague on the way to work, answering the phone for him when he's out of the room.

tunnelling: Every graduate physicist knows that there isn't a potential barrier so high that it can't be passed through by hanging around outside it long enough. So to 'tunnel' is to get where you don't belong simply by persistence. Hence ' $I$ see that at long last Jones has tunnelled his way into The Royal Society, the professorship etc. It sounds quite polite, even creditable, and suggests a certain amount of beavering; preferable to talking of Buggins' turn.

Do not confuse tunnelling with the ability of Hungarians to enter a revolving door behind vou and come out ahead of you. This is a genuine and quite cimple skill, and science has a word for it, too; spinflinning. Those subiected to it have been known to remark 'What's happening to this spin-flipping door?'

Christmas competition. Now that we have started you on the learning-curve, we would like to access your database of similar examples. $£ 10$ for the most outrageous entry received at Nature, 4 Little Essex St, London WC 2 by 6 Jan. 